\title{
NOME PRÓPRIO COMO LUGAR DE MEMÓRIA NA MÍDIA MINEIRA: REFLEXÕES SOBRE JORNAIS DE MARIANA
}

\author{
Alessandra Folha Mós Landim \\ Doutoranda em Estudos Linguísticos pela Universidade Federal de Minas Gerais (UFMG) \\ cna.alessandrafolha@gmail.com
}

\section{RESUMO}

Este trabalho tem como temática a ocorrência de nomes próprios em discursos da mídia impressa marianense que remontam à memória de uma mineiridade imanente aos textos analisados. Um recorte de três jornais marianenses foi feito e, dentre eles, foram selecionados alguns excertos de diferentes textos jornalísticos que utilizam nomes próprios como lugares de memória das marcas de mineiridade que constituem esses jornais. O artigo passa por uma reflexão sobre a dimensão memorial que constitui os discursos para então abordar brevemente a temática da mineiridade, que é tomada sob o escopo da ordem do imaginário social. Articulase tal noção à dimensão discursiva dos excertos analisados tomando os nomes próprios de mineiros, tais como Dom Silvério, Santos Dumont e Carlos Drummond de Andrade, como detentores de um sentido memorial que evoca valores constitutivos do imaginário de mineiridade.

Palavras-chave: nomes próprios, memória, imaginário, mineiridade, mídia impressa marianense.

\section{ABSTRACT}

This text aims at the emergence of proper names in discourses from Marianas' (MG) media that attach to the memory of a mineiridade immanent to the analyzed texts. We made a clipping of three newspapers from Mariana, and, among them, we selected excerpts from different journalistic texts. They show names as spaces of memory of mineiridade that constitutes these newspapers. The paper reflects on the memorial dimension that constitutes the discourses and then briefly discuss the theme of mineiridade, which is taken under the scope of the social imaginary order. It articulates this notion to the discursive dimension of the excerpts analyzed, taking the names of people from Minas Gerais, such as Dom Silvério, Santos Dumont and Carlos Drummond de Andrade, as holders of a memorial sense that evokes constitutive values of the imaginary of mineiridade.

Keywords: names, memory, imaginary, mineiridade, media of Mariana. 


\section{Primeiras palavras}

Este trabalho nasce de uma perspectiva sobre a mídia de Mariana (MG) como importante lugar de preservação da memória do povo mineiro e de sua identidade em coletividade. A materialização de traços memoriais sobre o que é ser mineiro é tomada como constitutiva da vida em sociedade e sob a égide da linguagem, sendo, dessa maneira, uma importante forma de pensar os discursos que constituem a mídia impressa mineira, especialmente no que tange a jornais que circularam na região de Mariana no século XX. Assim, examinamos uma coleção de excertos retirados de jornais regionais, produzidos e circulantes em Mariana à época mencionada, que resgatam valores do que é ser mineiro e do imaginário de mineiridade. O exame proposto neste trabalho se dará, portanto, por intermédio do uso de nomes próprios, de modo que possam ser tomados como importantes modelos de valores que representam os traços de um povo.

Os jornais marianenses têm nos mostrado que, além de outros fatores importantes, a utilização de nomes de mineiros de destaque nas construções discursivas de seus mais variados textos é expressivo elemento de exame da memória mineira e se mostra como importante componente de um patrimônio cultural manifesto por meio de diversas atividades sociais, dentre elas a própria atividade midiática regional.

Para além de um gentílico que marca meramente o lugar de nascimento de um indivíduo, consideramos que o ser mineiro se constrói nos processos de prática discursiva que alimentam e, ao mesmo tempo, resgatam valores que constroem uma "imagem" de um grupo. Como nos apegamos fortemente às noções de memória ancorados em análise discursiva, vale relembrar que "a reflexão sobre memória sempre esteve presente no quadro da Teoria da Análise do Discurso, muito embora, nos textos fundadores, esta 
nomeação ainda não tivesse tido lugar" (INDURSKY, 2011, p. 68). Assim, noções como pré-construído, repetição, paráfrase e a própria noção maingueneauniana de interdiscurso também corporizam as questões memoriais. Selecionamos, assim, três jornais que contêm enunciados significativos do ponto de vista de mineiridade e da utilização de nomes próprios como lugares de memória.

Sobre Voz de Marianna, podemos afirmar que i) é um jornal mineiro com edições em que se encontram textos paradigmáticos em relação à questão de mineiridade; ii) é um jornal marianense sobre temáticas que se encontram no entorno da cidade, sempre valorizando a sociedade mineira, preservando, dessa maneira, noções constitutivas de mineiridade e iii) é um jornal que circulou em Mariana no final da década de 80 . Os excertos selecionados para o exame dos nomes próprios são de edições de 1987 . O Germinal, por sua vez, que foi fundado em 1905, de acordo com a narrativa de suas próprias edições, é um jornal que se posiciona como Órgão dos interesses do município de Mariana, sendo, por isso, um jornal de cunho político, que se ocupa em preservar valores inerentes à noção de mineiridade, representando o que é ser mineiro sempre positivamente. É também um jornal que circulou por várias décadas na cidade de Mariana, podendo ser encontradas edições do início do século XX até meados do mesmo. Selecionamos textos para o exame dos nomes próprios que foram publicados na década de 1930. Já O Cruzeiro é um jornal que sempre se preocupou com acontecimentos sociais da cidade de Mariana, daí o resgate que o jornal faz de mineiros de destaque, sempre dando ênfase a noções que se amparam no imaginário da mineiridade. É um jornal que circulou em Mariana nas primeiras décadas do século XX, tendo expressiva publicação no âmbito das mídias impressas marianenses. Os enunciados que retiramos de suas edições também remontam à década de 1930 . 
É importante mencionar que a escolha desse recorte de enunciados não se ancora na temporalidade propriamente dita, mas nos focos temático e teórico-metodológico que nos amparam neste trabalho. Outra observação importante é que não estamos propondo uma análise extrema e aprofundada dos enunciados, mas nos ocupamos de demonstrar o modo como os nomes podem evocar sentidos variados, numa tentativa de refletir sobre a questão e não de fechá-la.

Para além das noções de mineiridade, nosso recorte se dá teóricometodologicamente nas noções de quadros pré-discursivos (PAVEAU, 2005), retomados e rememorados no sentido de cristalizar valores constitutivos de traços culturais em coletividade por meio de nomes próprios. Por isso, por intermédio do exame dos jornais, pudemos selecionar três nomes que se ocupam de preservar e difundir a memória da mineiridade: i) Dom Silvério, primeiro arcebispo de Mariana, que resgata os valores religiosos; ii) Santos Dumont, nascido na antiga cidade de Palmyra (hoje nomeada Santos Dumont dada a sua importância social), tendo sido tomado como um "paradigma" do que é ser mineiro e iii) Carlos Drummond de Andrade, representante dos traços culturais, tão valorizados do ponto de vista da mineiridade. O trabalho que ora apresentamos consiste em passarmos por uma seção de contextualização os elementos que constituem a noção de mineiridade para desembocarmos, então, em uma seção sobre o imaginário social e, finalmente em uma seleção de excertos desses jornais que, ancorados nesses elementos, se valem de nomes próprios para preservação da memória.

\section{Sobre o que é ser mineiro: elementos do imaginário de mineiridade}


Muitos traços culturais têm seu papel nas diferentes regiões do Brasil. Tais traços são reconhecidos como as características que constituem um grupo social em decorrência dos aspectos socioculturais e/ou localização geográfica. Assim, é por meio de certa generalização do que é ser mineiro que podemos iniciar nossa trajetória em relação ao imaginário de mineiridade e o modo como essa noção é construída no sentido que os nomes próprios carregam nos enunciados propostos adiante.

Sobre os nomes próprios que propomos para reflexão, ainda que tais personalidades sejam mineiras, é preciso compreender que "o mineiro não é apenas aquele nascido em Minas Gerais: é ainda um personagem envolvido por uma forte carga simbólica. Uma carga extraída da própria Minas - ou que Minas e os mineiros compartilham" (FRANÇA, 1998, p. 68). A questão da mineiridade pode ser construída, assim, a partir de uma ideia essencialista: ser mineiro não seria somente uma maneira de se diferenciar do outro numa dialética com o "não-mineiro", mas de se mostrar enquanto mineiro em todos os modos possíveis, em todos os "mundos" possíveis. Nesse sentido, a essencialidade do ser mineiro leva em conta uma série de contingências que condicionam o sujeito a reconhecer-se como tal por meio dos aspectos socioculturais somados às limitações geográficas do estado.

Além disso, é possível depreender sob a égide da mineiridade que

há uma "aura" em torno do nome de Minas. Quer se trate de montanhas, de sua história, de seus mitos de origem, de seus casos ou comportamento normal de sua gente; há em todo canto uma espécie de "alma mineira" sobre a qual muito já se falou, e a partir da mesma recortou-se e constituiu-se uma noção: a mineiridade (FRANÇA, 1998, p. 69) - grifo da autora. 
Essas concepções acerca da mineiridade nos levam ainda a uma perspectiva de noções de cultura como comunidades imaginadas. Dessa forma, a questão da mineiridade poderia ser tomada como uma ideia cultural da qual os mineiros compartilham em práticas linguageiras. Nesse sentido, essa noção não se trataria de uma verdade absoluta, mas de produto de imaginários e representações culturais, significações dadas pelos sujeitos sociais sobre sua vida em sociedade. Embora esteja mais ocupado da ideia de nação, emprestamos a noção de Stuart Hall para refletirmos sobre a vida em coletividade em Minas Gerais.

As culturas nacionais são compostas não apenas de instituições culturais, mas também de símbolos e representações. Uma cultura nacional é um discurso - um modo de construir sentidos que influencia e organiza tanto nossas ações quanto a concepção que temos de nós mesmos (...). As culturas nacionais, ao produzirem sentidos sobre a "nação", sentidos com os quais podemos nos identificar, constroem identidades. Esses sentidos estão contidos nas estórias que são contadas sobre a nação, memórias que conectam seu presente com seu passado e imagens que dela são construídas (HALL, 2006, p. 51).

Esses "sentidos sobre a nação", que podem muito apropriadamente ser desdobrados para sentidos sobre a mineiridade, são dados a partir de representações discursivas. Nesse aspecto, os textos jornalísticos marianenses nos revelam uma dimensão simbólica em cuja construção discursiva encontram-se componentes constitutivos de mineiridade. Por isso, é interessante compreender que "o contexto sócio histórico, a atmosfera cultural de uma sociedade não são elementos externos, mas fundadores das suas práticas de comunicação: o dizer de uma sociedade é uma cristalização daquilo que ela é" (FRANÇA, 1998, p. 61). 
Por outro lado, as noções do que é ser mineiro perpassam eventos históricos, como o processo de urbanização precoce da região que iniciou as atividades econômicas ali, especialmente à época aurífera (DIAS, 1985), bem como o próprio processo de colonização nas suas especificidades exploratórias. Questões como a "ideologia do trabalho", características de personalidade como a delicadeza, a obsequiosidade, o tato com as tradições e com a fé católica, também são elementos que auxiliaram historicamente na construção do perfil do que é ser mineiro (ARRUDA, 1990). Desde a tradição política de Minas Gerais, remontada ao período da Inconfidência, dos ideais de liberdade que evocaram o sentido de que Minas Gerais tem notoriedade política (ÂNGELO, 2006), até a galeria dos políticos mineiros que são ou deveriam ser homens de princípio (FRANÇA, 1998), a tradição política de Minas Gerais é outro elemento de grande importância nas construções representativas do que é ser mineiro.

O patriotismo e amor às causas liberais políticas são acompanhados ainda pela religiosidade, que "foi ganhando espaço desde seu [de Minas Gerais] processo de ocupação territorial" (NIERO, 2014, p. 128) e, embora fosse constituída como uma "religião de superfície voltada para o culto dos santos e forte penetração de elementos profanos" (FRANÇA, 1998, p. 78), constitui-se elemento imprescindível dos traços culturais do povo mineiro. A propósito da tradição religiosa, uma das questões que colocam em ação o compartilhamento de traços de mineiridade se encontra na importância da arte, especialmente a barroca. Além disso, a tradição artística se desdobra ainda para representações poéticas, como é o caso de Carlos Drummond de Andrade e sua obra. A geografia de Minas Gerais é também outra característica a ser mencionada, e isso porque "o relevo [do estado] passa a determinar o caráter dos habitantes de Minas" (ARRUDA, 1990, p. 126). E muito embora esse caráter seja marcado pelo isolamento da 
vida urbana, a imagem do homem de Minas como homem de montanha é sempre tecida entremeada de elogios e exaltações.

Todos esses elementos de mineiridade têm sua origem, em nosso ponto de vista, em práticas discursivas que incluem o compartilhamento de narrativas e de acontecimentos históricos que são rememorados e comentados. Dessa forma, essas práticas constroem e reforçam os elementos de mineiridade por meio de um imaginário sobre os sujeitos representantes desse gentílico.

\section{Considerações sobre a instituição imaginária da sociedade e sua relação com a perspectiva discursiva sobre mineiridade}

Pensar na noção de mineiridade do ponto de vista dos jornais impressos marianenses e na maneira como essa noção de ser mineiro perpassa seus textos, uma vez que são pontos de relevada importância na preservação da memória, nos levou a refletir sobre a necessidade de considerar a mineiridade como uma instituição imaginária. 0 imaginário que propomos se constitui de elementos simbólicos que tecem o mundo e os sujeitos. Para Castoriadis (1982), o imaginário é uma criação incessante e deve ser compreendido a partir da postulação de que

aqueles que falam de "imaginário" compreendendo por isso o "espetacular", o reflexo ou o "fictício", apenas repetem, e muito frequentemente sem o saberem, a afirmação que os prendeu para sempre ao um subsolo qualquer da famosa caverna: é necessário que (este mundo) seja a imagem de alguma coisa. O imaginário de que falo não é a imagem de. É criação incessante e essencialmente indeterminada (social-histórica e psíquica) de figuras/formas/imagens, a partir das quais somente é possível falar-se de "alguma coisa". Aquilo que denominamos "realidade" e "racionalidade" são seus produtos (CASTORIADIS, 1982, p. 13). 
Assim, os elementos que ancoram os discursos de mineiridade não derivam da realidade. Antes, são algo que dá origem à própria "realidade" significada e mantida por intermédio do compartilhamento da memória que, por sua vez, só pode ser depreendida por intermédio do mundo das significações, ou seja, das práticas linguageiras. Podemos ainda compreender, nesse aspecto, que o imaginário não se separa da "realidade" definida por meio das práticas de significação que a constituem como tal.

Ainda segundo Castoriadis,

quanto ao "real" do mundo humano, não é somente enquanto objeto possível de conhecimento, é de maneira imanente, no seu ser em si e para si, que ele é categorizado pela estruturação social o imaginário que este significa; relações entre indivíduos e grupos, comportamentos, motivações, não são somente incompreensíveis para nós, são impossíveis em si mesmos fora deste imaginário (CASTORIADIS, 1982, p. 193).

Seguindo essa linha, compreendemos que é o imaginário do que é ser mineiro que dá origem à noção de mineiridade e que é essa noção que amarra os discursos dos jornais impressos marianenses por intermédio, dentre outros fatores, da utilização de nomes próprios como significativos do ponto de vista de conservação da memória de mineiridade.

Para finalizarmos a noção de imaginário, podemos ainda rapidamente desdobrá-la no sentido de saberes que circulam em coletividade e que, na medida em que são significados nas atividades que envolvem a linguagem, são percebidos como imaginários sócio-discursivos, aqueles que são materializados na prática discursiva (CHARAUDEAU, 2006). Dessa forma, "os grupos sociais produzem discursos de configuração diversa que 
dão sentido a essas materializações" (CHARAUDEAU, 2006, p. 206). Assim, tomar a noção de mineiridade também desse ponto de vista nos ampara no sentido de compreender que as significações sobre o que é ser mineiro por meio da utilização de nomes próprios nas práticas discursivas dos jornais auxilia no processo de preservação da memória de mineiridade.

\section{Nomes próprios como elementos memoriais: resgate de noções de mineiridade nos discursos da mídia impressa marianense}

Ancorados na noção de que os imaginários são sócio-discursivos, na medida em que são compartilhados por meio de atividades linguageiras e que esse funcionamento é um dos responsáveis pela preservação da memória mineira, tomamos para análise nesta seção excertos representativos dos discursos que se apoiam e/ou são constitutivos desse imaginário de mineiridade. Nesses discursos, encontramos os nomes próprios sendo utilizados como veiculadores da memória mineira, ou seja, os nomes estão carregados de uma significação que não se restringe somente à pessoa, mas àquilo que ela representa. De acordo com Paveau (2005), podemos tomar o imaginário como quadros prédiscursivos, elementos nos quais o discurso se apoia para compartilhar as noções do que é ser mineiro. É importante que utilizemos a formulação da autora em que aborda a questão de uma memória que não se atém somente a uma memória social, mas também a uma memória do discurso. Assim, "a memória discursiva é, com efeito, um conceito que [...] visa a ancorar a análise do discurso na história, integrando os tempos (curtos, médios ou longos) da memória no estudo da materialidade linguageira" (PAVEAU, 2005, p. 2). 
Se afunilarmos um pouco mais essa noção em um recorte temático, podemos afirmar que a memória dos discursos que é materializada nos jornais está estreitamente ligada às condições do imaginário de mineiridade. Assim, não estamos ligados tão e somente uma questão gentílica, mas nos relacionamos diretamente com as condições históricas que têm a ver com a preservação desses traços culturais materializados nos discursos. Um exemplo paradigmático em relação a essa questão está no jornal $O$ Germinal, onde encontramos:

Completou-se a 29 do mês $p$. findo o nono aniversário da morte, sempre lembrada e sempre sentida, de extraordinário e insigne prelado $\mathrm{D}$. Silvério Gomes Pimenta. Este nome, dos mais ilustres e respeitáveis de toda Minas, vive indelével na memória não só de quantos o conheceram atravez de suas obras mas ainda de todos que lhe sentimos de perto as flâmulas sublimes das excelsas virtudes e incomparável saber ( $O$ GERMINAL, 9 de setembro de 1931, p. 1).

Nesse excerto, podemos perceber que o nome do primeiro arcebispo de Mariana evoca rememorações de seus feitos na sociedade mineira. Além de ancorar-se na religiosidade, o próprio jornal afirma que o nome do arcebispo é um dos mais importantes de Minas Gerais. Dessa maneira, por ser importante representante da religião católica, seu nome é perpassado por significações constitutivas do imaginário de mineiridade, sendo lembrado mesmo depois de completada quase uma década de sua morte. É possível compreender, por meio desse excerto, que o jornal se posiciona em relação à valorização de seus feitos e o coloca em lugar de importância na sociedade mineira, transmitindo, assim, esse quadro pré-discursivo que auxilia na preservação de sua memória. 
Não somente o aniversário de morte de D. Silvério é mencionado, mas o próprio aniversário de nascimento do arcebispo é rememorado em $O$ Germinal, exemplificando mais uma vez os elementos do imaginário de mineiridade e/ou os quadros pré-discursivos que apontam para a base dessa construção discursiva:

A funda admiração que sempre nos mereceu o inegualável prelado, cujo nome temam por título estas linhas, não nos permite esquecer, sem embargo dos annos volvidos, a data em que lhe festejava o anniversário de seu nascimento. (...)

As suas obras de benemerência, os seus feitos reveladores de entranhado amor à humanidade, gravaram no coração de todos o seu augusto nome. E assim o dia 12 de janeiro será entre nós sempre venerado, como se veneram os dias santificados (O GERMINAL, 24 de janeiro de 1932, p. 1).

A lembrança dos feitos do arcebispo é colocada em jogo nesse excerto de modo a evocar valores do catolicismo com expressões como "obras de benemerência" e "feitos de amor à humanidade". O trecho "gravaram no coração de todos o seu augusto nome" ainda reforça a importância do nome do prelado. É possível, então, compreender que a relação entre a utilização de nomes próprios como lugares de memória é uma categoria que utilizamos para o exame desses discursos da mídia marianense, que se mostra bastante produtiva, de modo que os discursos ancorados no imaginário de mineiridade são perceptíveis ao exame dos jornais marianenses impressos.

Para Paveau, o nome próprio tem "capacidade de indicar vários referentes ao mesmo tempo, sem que se possa identificá-los sempre e atribuir-lhes uma ordem de prioridade" (PAVEAU, 2007, p. 327). Por isso, compreendemos que ele invoca noções prédiscursivas que se relacionam de perto com o imaginário de mineiridade nos exemplos 
sobre os quais estamos refletindo. Isso se refere tanto ao nome de Dom Silvério quanto ao nome de Santos Dumont, sobre o qual leremos os excertos a seguir:

Este feito do glorioso mineiro, que foi motivo de pasmo dos que presenciaram, lá na pátria das luzes, encheu-nos, a nós brasileiros de justo orgulho. Foi a abertura promissora da navegação aérea, que o saudoso compatriota sonhara vir beneficiar a humanidade.

O gênio, que surgiu nas montanhas mineiras, revelou aos franceses e ao mundo a possibilidade da travessia do espaço, sobre as asas de poderosas machinas velozes, vencedoras de largas distâncias ( $O$ GERMINAL, 15 de dezembro de 1932, p. 4).

E ainda:

O desaparecimento de Santos Dumont, do sábio descobridor da navegação aérea, abalou não somente a pátria de seu nascimento, mas ainda o mundo e sobretudo a França, que o acolhera e glorificara, em vida.

Muitas homenagens the têm sido merecidamente prestadas, entre as quaes figura singular e notável, a do povo e autoridades de Palmyra, berço do imortal Albert Santos Domunt, que numa prova de clavado civismo e veneração do maior de seus conterrâneos, pleitearam em bôa hora e conseguiram do Presidente Olegário Maciel a mudança para Santos Dumont, do nome da cidade de Palmyra.

Se já não estivesse indelével no coração de todos o nome do ilustre morto, ligado como está a uma das mais notáveis invenções do nosso século, torna-lo-ia imperecível entre os brasileiros a magnífica lembrança do povo de Palmyra, lembrança que um nobre gesto do povo de Minas a seu glorioso filho, que tão alto elevou o nome de sua Pátria (O GERMINAL, 15 de dezembro de 1932, p. 4).

Os excertos acima, encontrados na notícia sobre a homenagem a Santos Dumont (mudança de nome da cidade de Palmyra para "Santos Dumont"), morto naquele ano, representam a carga de significados que seu nome evoca enquanto mineiro. Perpassados pelo valor do patriotismo, que é desdobrado logo adiante pela menção ao seu lugar de 
nascimento ("o gênio que surgiu nas montanhas mineiras"), os enunciados carregam-se de sentimento de orgulho por o inventor ter sido um brasileiro e um mineiro ilustre. Em uma construção discursiva que remonta até mesmo ao gênero retórico epidítico, os enunciados sugerem a relevância de seus feitos e a significativa representação de um mineiro "imortal".

A mudança de nome da cidade de Palmyra para Santos Dumont também foi tratada pelo jornal $O$ Cruzeiro. Embora rico em expressões líricas, o texto é uma notícia, onde lemos:

Merece, entretanto registro especial, pela expressiva eloquência, do gesto, a significativa lembrança do povo da antiga cidade de Palmyra, no Estado de Minas Geraes, plantada nas fraldas da Mantiqueira em cujo azulino infindo de suas montanhas - grandes como foi Santos Dumont - veio à luz do dia a glória cuja perda a humanidade hoje deplora. O povo de Palmyra e suas autoridades, em empolgante movimento cívico, tão logo conhecido o rude golpe que feriu, num repente o Brasil, solicitou, por intermédio de seu Prefeito Jacques Gabriel Pansardi, ao Presidente Olegário Maciel, a mudança do nome de Palmyra para Santos - Dumont, no que foram prontamente atendidos.

Assim, o nome do glorioso patrício nosso, preside hoje, como um nome tutelar, a grande atividade do povo sandumonense, sem dúvida, legitimamente orgulhoso, como nós, da existência fecunda do gênio maior do século XX.

Foi, não há dúvida, essa homenagem melhor que a gente montanhesa poderia prestar á memória imortal de ALBERTO SANTOS DUMONT (O CRUZEIRO, 24 de fevereiro de 1933, p. 2).

Do ponto de vista do imaginário de mineiridade, bem como do estilo elogioso, este excerto é, sem dúvidas, um dos mais expressivos. Numerosos elementos que constituem o imaginário de mineiridade colocados em uso na prática discursiva podem ser observados. Assim, a mudança de nome da cidade está intimamente ligada aos ideais de mineiridade em um movimento que vai além da notícia em questão: propor a 
mudança de nome de uma cidade difunde uma memória ligada neste excerto por expressões como "fraldas da Mantiqueira", "azulino infindo de suas montanhas" e "gente montanhesa". Além disso, promove o nome de Santos Dumont, perpetuando-o por meio do novo nome dado à sua cidade natal. Apesar dessas expressões, no entanto, percebemos, por meio da denominação de Santos Dumont como "patrício nosso", uma alusão ao gentílico "mineiro". Ademais, o excerto parece fazer questão de deixar claro que o gentílico da região onde nascera o inventor também fora alterado, passando a ser "sandumonense", o que carrega ainda mais semanticamente o nome de Santos Dumont.

Os nomes de Santos Dumont e Dom Silvério são acompanhados pelo nome de Carlos Drummond de Andrade em outro jornal marianense: Voz de Marianna. Em um poema do final da década de 1980, o poeta é descrito como importante mineiro:

\section{DRUMMOND!}

Você partiu!/ Você vivia!.../ vivia em tudo/ nas ondas do mar/ no sol brilhando/ nas estrelas iluminando./ Mas, você partiu.../ Você está distante sorrindo/ Vendo que todos choram./ Por quê?/ Por que você partiu?/ Você não é mais o mesmo Drummond/ Mas sua poesia será eterna/ Você que cantou a sua Itabira em versos e prosas./ Você que em 18 de agosto nos deixou indo para junto de Deus compor versos/ Mas como você mesmo disse: "Quero a paz das estepes/ a paz dos descampados/ a paz do Pico de Itabira./ Agora serei eterno"/ Saudades DRUMMOND (VOZ DE MARIANNA, outubro de 1987, p. 7).

Esse poema, publicado pelo jornal em uma de suas páginas, sem pretensões noticiosas (visto que a notícia de sua morte fora dada em agosto do mesmo ano), 
dedicado ao poeta que morrera há pouco desde a data de sua publicação, dá destaque ao seu lugar de nascimento, além de ser constituído por uma intertextualidade com o próprio poema de Drummond. Da mesma forma, aludir à morte do poeta em um eufemismo que se relaciona diretamente com a fé católica (ir aos braços de Deus) remonta à religiosidade mineira. Neste poema, podemos ainda depreender que as manifestações culturais que se dão por meio de construções artísticas são de grande valor nos jornais mineiros, sendo, portanto, um dos elementos que nos evocam manifestações do imaginário de mineiridade.

Esses três excertos são representativos dessa noção de preservação da memória mineira que se dá por meio de práticas de uso da linguagem que, por sua vez, remontam aos quadros de saberes disponíveis para os enunciadores que são preservados e compartilhados, estando ligados, todavia, a imaginários que, além de constituir as práticas discursivas e os discursos, são ancoragens dos mesmos, dando a entender que existe nessa atividade enunciativa uma interdependência entre o que é produzido linguístico-discursivamente e seus elementos de embasamento. Dessa forma, os nomes próprios aqui apresentados referem-se à rede de significações de elementos de mineiridade, assumindo papel de designadores dotados de saberes compartilhados sobre o imaginário de mineiridade (PAVEAU, 2007).

\section{Palavras finais}

As reflexões propostas neste trabalho têm como principal objeto a análise dos nomes próprios como designadores de memória de uma mineiridade que perpassa os textos jornalísticos marianenses em questão. A análise não explorou com afinco as 
questões de gênero textual e gênero discursivo, o que, certamente poderá ser mais bem desenvolvido em retomadas desse estudo.

Uma das possibilidades de desenvolvimento das pesquisas sobre os jornais marianenses certamente passa pelo aprofundamento das análises no sentido de explorar ainda mais a materialidade do texto na construção do imaginário de mineiridade. Este artigo, no entanto, teve como objeto o trabalho de reflexão sobre os nomes próprios na construção e no resgate de valores que constroem o imaginário de mineiridade. Nesse sentido, além dos excertos utilizados neste trabalho, com destaque para os nomes próprios como designadores de mineiridade, outros nomes são rememorados nos jornais marianenses, tais como Tiradentes, Tancredo Neves e Aleijadinho, corroborando o imaginário de mineiridade. Para além desses nomes, ainda testemunhamos o manuseio de jornais marianenses, menções a Alphonsus de Guimaraens, à própria cidade de Mariana como depositária da memória de mineiridade, Monsenhor Horta, Arthur Bernardes, Antonio Carlos, Olegário Maciel, Dom Frei Manoel da Cruz (primeiro bispo de Minas Gerais) e tantos outros diretamente vinculados com a preservação da memória mineira.

Pareceu-nos, dessa maneira, bastante ilustrativo, a propósito de tais nomes, utilizar com mais detalhamento as publicações de $O$ Germinal (a respeito de D. Silvério, prelado/arcebispo de Mariana-MG e Santos Dumont), de O Cruzeiro (na notícia sobre a mudança de nome da cidade de Palmyra) e de Voz de Marianna (no poema publicado sobre Drummond) como exemplos de nomes utilizados como designadores que evocam uma memória discursiva e que, além disso, "transportam" um imaginário de mineiridade a um "reino de significações prévias" que não necessariamente estaria materializado discursivamente (não obstante esteja), confirmando a hipótese de Paveau no que diz 
respeito aos "pré-discursos como quadros anteriores, transmitidos de discurso em discurso através do tempo" (PAVEAU, 2007, p. 325).

Nas ilustrações que utilizamos em relação à categoria dos nomes como designadores, pudemos compreender, então, que as reflexões da autora sobre os nomes e seu elo com os quadros pré-discursivos nos podem servir de fundamento para os apontamentos que procuramos fazer neste trabalho. Por isso, esses quadros prédiscursivos que relacionamos com o imaginário de mineiridade "são quadros de saber, de crença e de prática" (PAVEAU, 2007, p. 318), o que nos autoriza a pensar que os nomes que apontamos neste trabalho representam e materializam discursivamente esses saberes e crenças especialmente no que se refere ao imaginário de mineiridade.

\section{Referências}

ÂNGELO, Marcel Henrique. O uso da linguagem na constituição da identidade: o exemplo do 'político mineiro'. Revista Científica da FAMINAS, Muriaé, n. 3, p. 159-174, 2006.

ARRUDA, Maria A. do Nascimento. Mitologia da mineiridade. São Paulo: Brasiliense, 1990. CASTORIADIS, Cornelius. A instituição imaginária da sociedade. Rio de Janeiro: Paz e Terra, 1982.

CHARAUDEAU, Patrick. Discurso político. São Paulo: Contexto, 2006.

DIAS, Fernando Correia. Mineiridade: construção e significado atual. Ciência e Trópico, Recife, Dipes/Fundaj, n. 1, p. 73-89, 1985.

FRANÇA, Vera Veiga. Jornalismo e vida social: a história amena de um jornal mineiro. Belo Horizonte: Editora UFMG, 1998.

HALL, Stuart. A identidade cultural na pós-modernidade. 11. ed. Rio de Janeiro: DP\&A, 2006. 
INDURSKY, Freda. Remontando de Pêcheux e Foucault: uma leitura em contraponto. I Seminário de Estudos em Análise do Discurso: Michel Pêcheux e a Análise de Discurso: uma relação de nunca acabar, Porto Alegre: Instituto de Letras, 2003. Disponível em: <http://www.ufrgs.br/analisedodiscurso/anaisdosead/1SEAD/Paineis/Fredalndursky.pdf> . Acesso em: 13 mar. 2017.

PAVEAU, Marie-Anne. Reencontrar a memória. Percurso epistemológico e histórico. Disponível em: <http://www.analisedodiscurso.ufrgs.br/anaisdosead/sead2.html>. Acesso em: 28 ago. 2018 (2005).

Recebido em 28 de agosto de 2018.

Aceite em 21 de novembro de 2018. 